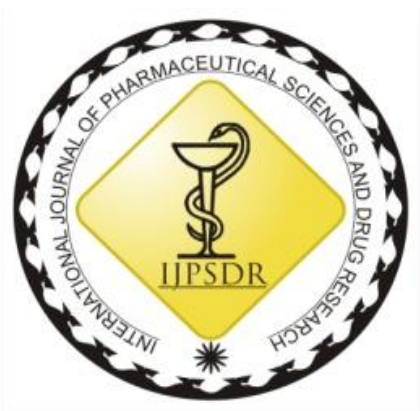

ISSN: 0975-248X

RESEARCH ARTICLE CODEN (USA): IJPSPP

(cc) EY-NC-SA

\title{
Formulation and Evaluation of Copper Nanoparticles Loaded Microsponges
}

\author{
S. Kothai, R. Umamaheswari* \\ Ethiraj College for Women, Chennai-600 008, Tamil Nadu, India
}

Copyright (C) 2019 S. Kothai et al. This is an open access article distributed under the terms of the Creative Commons AttributionNonCommercial-ShareAlike 4.0 International License which allows others to remix, tweak, and build upon the work non-commercially, as long as the author is credited and the new creations are licensed under the identical terms.

\begin{abstract}
Microsponges become imperative in the field of targeted drug delivery and in other biomedical applications. There was a clamant need for designing microsponges incorporating with green synthesised metal nanoparticles rather than the chemical drug in order to reduce the side effects of the drug and thus increasing the effectiveness of nature of the whole material. It provokes us to design this novel approach of loading copper nanoparticles into the microsponges. Here in this work, microsponges based on ethyl cellulose and polyvinyl alcohol were synthesised by Quasi-Emulsion Solvent diffusion method in which copper nanoparticles procured from Hibiscus rosa-sinensis leaf extract was incorporated. The Loaded microsponges were characterised by High Resolution Scanning Electron Microscopy (HR-SEM) and Particle size distribution Analyzer (PSA). The Drug content and Entrapment Efficiency of the microsponges were found out. The antimicrobial and antioxidant activity of the loaded microsponges were evaluated.
\end{abstract}

Keywords: Copper nanoparticles, microsponges, HRSEM, PSA, antimicrobial, antioxidant.

\begin{tabular}{l}
\hline DOI: 10.25004/IJPSDR.2019.110407 Int. J. Pharm. Sci. Drug Res. 2019; 11(4): 141-146 \\
\hline \\
*Corresponding author: Mrs. R. Umamaheswari \\
Address: Department of Chemistry, Ethiraj College for Women, Chennai-600 008, Tamil Nadu, India \\
E-mail $₫:$ aarthi.r90@gmail.com \\
Relevant conflicts of interest/financial disclosures: The authors declare that the research was conducted in the absence of any commercial or \\
financial relationships that could be construed as a potential conflict of interest. \\
Received: 26 June, 2019; Revised: 25 July, 2019; Accepted: 26 July, 2019; Published: 30 July, 2019 \\
\hline
\end{tabular}

\section{INTRODUCTION}

Microsponges are polymeric delivery systems, possessed of porous polymeric microspheres that can entrap active ingredients. These are tiny sponge like spherical particles that consists of myriad of interconnecting voids with large porous surface. Usually the size of the microsponges range from 5 to $300 \mu \mathrm{m}$. [1-2] Metal nanoparticles such as gold, silver and copper are reported as highly toxic to micro-organisms. ${ }^{[3-4]}$ In recent years, it has been extensively used for the production of medical products like wound dressing because of its strong cytotoxicity. [4-6] In current scenario, the development of microsponge loaded with specific drug has been emphasised due to their controlled release of the drug. Since the microsponges prepared from synthetic polymers, it will protect the entrapped drug from any kind of degradation. These kinds of encapsulated drugs within microsponge system can significantly reduce the irritation, side effects of the drug without decreasing its efficiency. ${ }^{[7-8]}$ The current work involves the formulation and evaluation of copper nanoparticles loaded microsponges and its biomedical applications. Here, microsponges were synthesised by Quasi-Emulsion 
Solvent diffusion method using different proportions of ethyl cellulose and polyvinyl alcohol. Later, the green synthesised copper nanoparticles from the leaf extract of Hibiscus rosa-sinensis were incorporated into the microsponges. The formulated and loaded microsponges were characterised by SEM and PSA. The Drug Content and Entrapment Efficiency of the loaded microsponges were studied. The antimicrobial and antioxidant activity of the copper nanoparticles loaded microsponges were evaluated.

Hence, in the present work an attempt was made for the first time by incorporating copper nanoparticles in the microsponges rather than any chemical drug. These metal nanoparticles loaded microsponges will minimise the toxicity of the drug intake, prolong the pharmacological effect and thus improve the overall effect of the microsponges. The copper nanoparticles loaded microsponges will show enhanced activity towards biomedical applications than the copper nanoparticles alone. In future, this study would lead to a new scenario of introducing copper nanoparticles loaded microsponges for a smarter application.

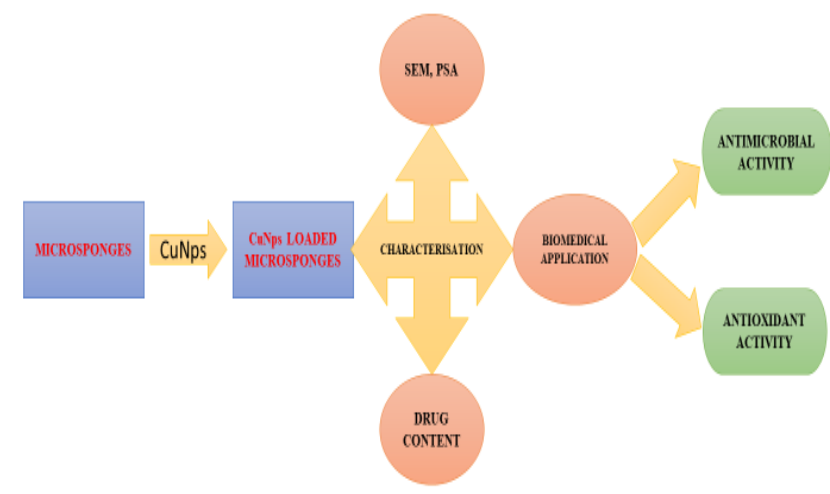

Fig. 1: Graphical Abstract of the current work

\section{MATERIALS AND METHODS \\ Materials}

Ethyl Cellulose (EC), Polyvinyl alcohol (PVA), Dichloromethane (DCM) of reagent grade were kindly purchased and used without purification. Copper nanoparticles were green synthesized from the leaf extract of Hibiscus rosa-sinensis. Double Distilled water was used throughout the study.

\section{Green synthesis of copper nanoparticles}

The Copper nanoparticles (B) were synthesized from the leaf extract of Hibiscus rosa-sinensis. The fresh leaves were collected and washed with distilled water to remove dust and impurities and shade-dried for 3-4 days at room temperature. About $100 \mathrm{~g}$ of dried and minced leaves were weighed and transferred to beaker containing $100 \mathrm{~mL}$ distilled water. It was then boiled at $60^{\circ} \mathrm{C}$ for $10-15 \mathrm{~min}$. First, the prepared solution was filtered Whatmann no.1 Filter paper to get a clear solution. This filterate was known as Hibiscus rosasinensis leaf extract. $50 \mathrm{~mL}$ of this extract was added to $50 \mathrm{~mL}$ of $0.05 \mathrm{M} \mathrm{CuSO}_{4}$, kept for incubation for 3 days.
After incubation, the precipitate got settled down that was confirmed by the colour change from green to black. This indicates the formation of Copper nanoparticles that was purified by repeated centrifugation at $6000 \mathrm{rpm}$ for $10 \mathrm{~min}$ to remove unwanted materials. The synthesized $\mathrm{CuNps}$ were lyophilized and stored at $25^{\circ} \mathrm{C}$ for further use. [9]

Synthesis of copper nanoparticles loaded Microsponges

Copper nanoparticles loaded Microsponges were formulated by Quasi-Emulsion Solvent Diffusion method. Five batches of microsponges $\left(\mathrm{NS}_{0}-\mathrm{NS}_{4} \mathrm{Cu}_{\mathrm{B}}\right)$ with varying proportions of Ethyl Cellulose (EC) and Polyvinyl alcohol (PVA) were taken. The Dispersed Phase consists of Copper Nanoparticles (B -CuNps) and required amount of EC dissolved in $20 \mathrm{~mL}$ of Dichloromethane (DCM). It was slowly added to PVA in $150 \mathrm{~mL}$ of aqueous continuous phase. Then it was stirred at $1000 \mathrm{rpm}$ under magnetic stirrer for 3 hours. The microsponges formed were filtered and dried in oven at $40-50^{\circ} \mathrm{C}$ for 24 hours. Then the dried microsponges were stored in vacuum dessicator to remove the residual solvent. The composition of the microsponge formulation was tabulated in Table 1. The Figure 2 indicates the schematic representation of microsponge formation. The prepared microsponges were characterized based upon the entrapment efficiency and particle size. [8]

Table 1: Formulation of Nanosponges with (B) CuNps

\begin{tabular}{cccccc}
\hline $\begin{array}{c}\text { Sample } \\
\text { Code }\end{array}$ & $\begin{array}{c}\text { Copper } \\
\text { Nanoparticles (B) } \\
\text { mg }\end{array}$ & $\begin{array}{c}\text { PVA } \\
\mathbf{g}\end{array}$ & $\begin{array}{c}\text { EC } \\
\mathbf{g}\end{array}$ & $\begin{array}{c}\text { DCM } \\
\mathbf{m L}\end{array}$ & $\begin{array}{c}\mathbf{H}_{\mathbf{2}} \mathbf{O} \\
\mathbf{m L}\end{array}$ \\
\hline $\mathbf{N S 0}$ & - & 2 & 2 & 20 & 150 \\
$\mathbf{N S}$ & 10 & 2 & 2 & 20 & 150 \\
$\mathbf{N S}_{\mathbf{1}} \mathbf{C} \mathbf{u}_{\mathrm{B}}$ & 10 & 2 & 3 & 20 & 150 \\
$\mathbf{N S}_{3} \mathbf{C u}$ & 10 & 3 & 2 & 20 & 150 \\
$\mathbf{N S}_{4} \mathbf{C u}$ & 10 & 3 & 3 & 20 & 150 \\
\hline
\end{tabular}

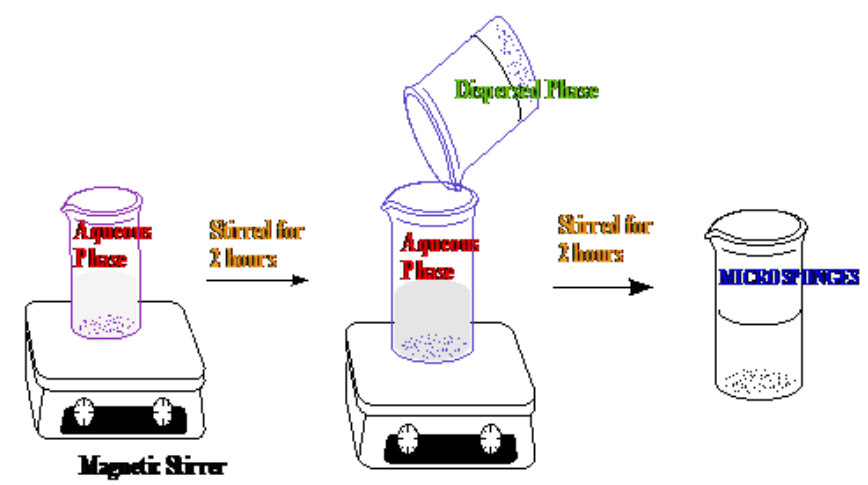

Fig. 2: The schematic representation of microsponges formation.

Characterisation of Copper nanoparticles loaded Microsponges

Microscopic studies

The morphology of the loaded microsponges and unloaded microsponges was studied by using High Resolution Scanning Electron Microscopy (HRSEM). Here we have used VEGA3 TESCAN instrument for our characterization work. A thin film of the sample 
was made by placing a pinch of the sample on a carbon coated grid and then the film on the SEM grid was made to dry under mercury lamp for 5 minutes.

Particle size determination

The particle size of the copper nanoparticles loaded Microsponges was determined by using Particle Size Distribution Analyzer. Here the instrument used was HORIBA Laser Scattering Particle Size Distribution Analyzer LA-950.

\section{Percentage Yield}

The percentage yield of copper nanoparticles loaded microsponges of various batches were calculated using the weight of final product after drying with respect to the initial total weight of drug and polymer used for the preparations. ${ }^{[8]}$

\section{Drug Content and Entrapment Efficiency}

About $10 \mathrm{mg}$ of microsponge from all batches were accurately weighed and dissolved in methanol in 50 $\mathrm{mL}$ standard flask and then made up to the volume of phosphate buffer $\mathrm{pH}$ 7.4. After appropriate dilution, the amount of drug was detected by a UV Spectrophotometric method at $650 \mathrm{~nm}$ using blank microsponges treated in the same manner. [8] The Entrapment Efficiency was calculated according to the following equation:

Entrapment Efficiency $(\%)=$ [Actual drug content in microparticles/Theoretical drug content] $\times 100$

Preparation of Standard Calibration Curve

Preparation of Phosphate Buffer $\mathrm{pH} 7.4$

Phosphate Buffer was prepared and $\mathrm{pH}$ was found to be 7.4 using digital $\mathrm{pH}$ meter. ${ }^{[8]}$

Determination of $\lambda$ max of copper nanoparticles

The absorption maxima for copper nanoparticles (B) were found to be $650 \mathrm{~nm}$. [9]

Standard calibration curve of Copper nanoparticles (B)

The absorbance of copper nanoparticle standard solutions having a concentration range of 100$500 \mu \mathrm{g} / \mathrm{mL}$ in phosphate buffer $\mathrm{pH} 7.4$ was plotted. The curve was found to be linear at $\lambda \max 650 \mathrm{~nm}$. The calculation of the drug content and Entrapment efficiency were based on this calibration curve. [8]

In- vitro antimicrobial study

Determination of Minimum inhibitory concentration (MIC) using Resazurin Microtitre Assay

Preparation of resazurin solution

The resazurin solution was prepared by dissolving 270 $\mathrm{mg}$ in $40 \mathrm{~mL}$ of sterile distilled water. A vortex mixer was used to ensure that it was a well-dissolved and homogenous solution.

Test was carried out in a 96 well Plates under aseptic conditions. A sterile 96 well plate was labelled. A volume of $100 \mu \mathrm{L}$ of sample was pipetted into the first well of the plate. To all other wells $50 \mu \mathrm{L}$ of nutrient broth was added and serially diluted it. To each well $10 \mu \mathrm{L}$ of resazurin indicator solution was added. $10 \mu \mathrm{L}$ of bacterial suspension was added to each well. Similarly, the same set up was performed for antifungal activity in which $50 \mu \mathrm{L}$ of potato dextrose broth was added and $10 \mu \mathrm{L}$ of fungal suspension was added on each well. Each plate was wrapped loosely with cling film to ensure that bacteria did not become dehydrated. The plate was incubated at $37^{\circ} \mathrm{C}$ for $18-24$ hours. The colour change was then assessed visually. Any colour changes from purple to pink or colourless were recorded as positive. The lowest concentration at which colour change occurred was taken as the MIC value. [9]

Antioxidant study

Determination of scavenging activity by DPPH assay

The percentage of antioxidant activity (AA \%) of each substance was assessed by DPPH free radical scavenging assay. Different concentrations of sample were added to all the tubes except blank. Then $3 \mathrm{~mL}$ of ethanol and $0.3 \mathrm{~mL}$ of $0.5 \mathrm{mM}$ DPPH radical solution in ethanol was added. The control solution was prepared by mixing ethanol $(3.5 \mathrm{~mL})$ and DPPH radical solution $(0.3 \mathrm{~mL})$. Absorbance was read at $517 \mathrm{~nm}$ after $30 \mathrm{~min}$ of reaction. [9] The scavenging activity percentage (AA

$\%)$ was calculated using the below formula

$\%$ Antioxidant activity $=\{($ absorbance at blank $)-$ (absorbance at test) / (absorbance at blank) $\} \times 100$

\section{RESULTS AND DISCUSSION}

\section{Microscopic studies}

From SEM studies, it was found that the samples had porous and almost spherical sponge in nature. The pores were induced by the diffusion of the solvent. [8] The SEM image of CuNps(B) were spherical and agglomerated to form clusters (Fig. 3). [9] The unloaded Microsponges shows shiny smooth surface morphology (Fig. 4). The Loaded microsponge shows porous smooth surface and spherical (Fig. 5). SEM results revealed that surface morphology has been shown to be beneficial for topical application for future studies.

\section{Particle size}

The Particle size analysis of loaded and unloaded microsponges (Fig. 6) revealed that the particle size ranges from $65 \mu \mathrm{m}$ to $93 \mu \mathrm{m}$. $\mathrm{NS}_{4} \mathrm{Cu}_{\mathrm{B}}$ was selected for the further study in terms of lower particle size $(65 \mu \mathrm{m})$. The smaller particle size shows better entrapment efficiency in future.

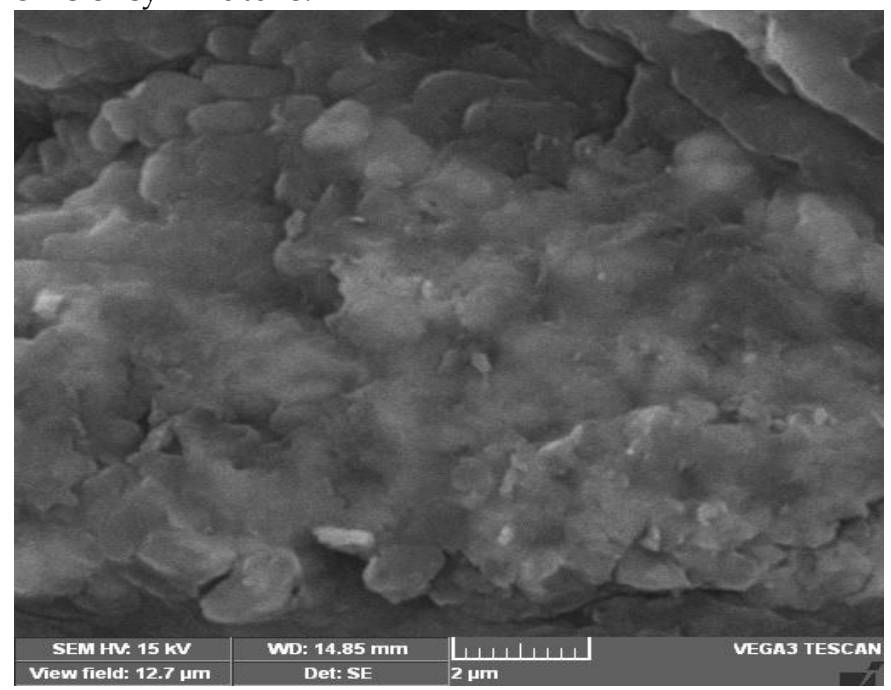

Fig. 3: SEM photomicrograph image of Copper Nanoparticles (B) 


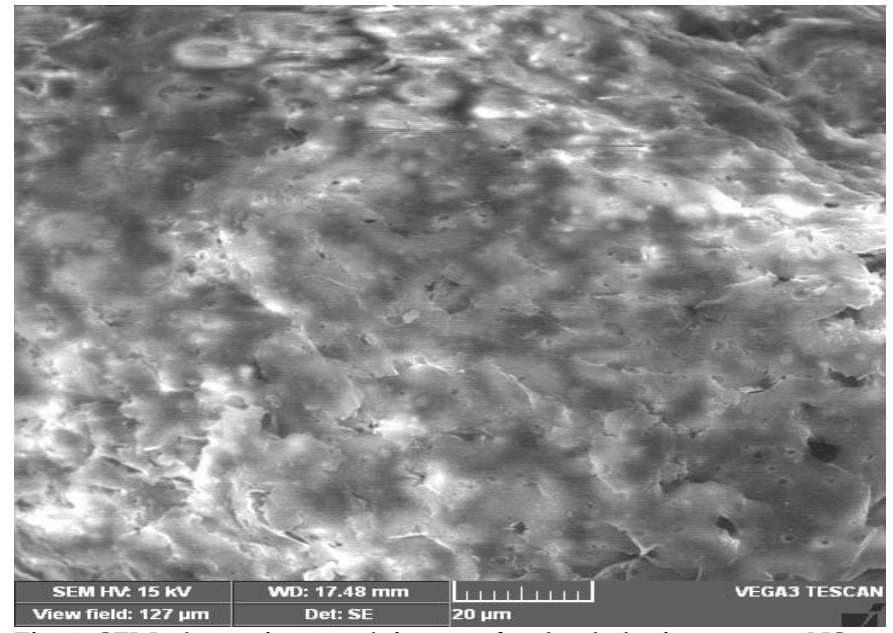

Fig. 4: SEM photomicrograph image of unloaded microsponge $\mathrm{NS}_{0}$

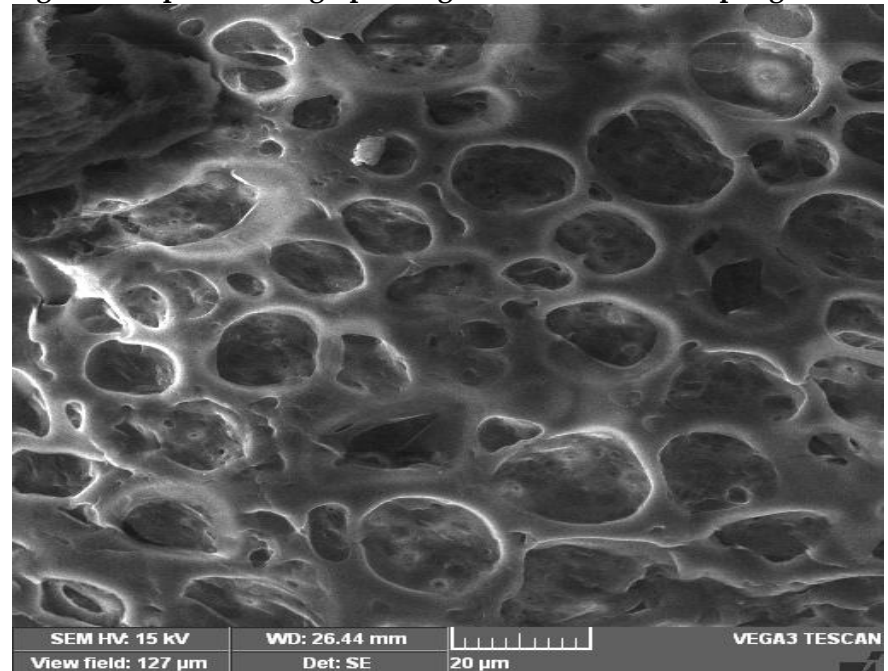

Fig. 5: SEM photomicrograph image of loaded microsponge $\mathrm{NS}_{4} \mathrm{Cu}_{\mathrm{B}}$ Particle size $(\mu \mathrm{m})$

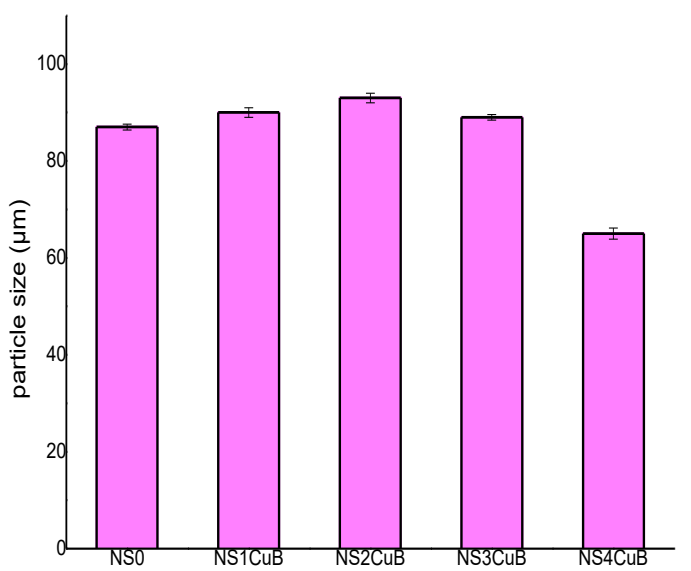

Fig. 6: Particle size of loaded and unloaded Microsponges

\section{Production yield}

The production yield of all the microsponges were calculated and shown in the Fig. 7.

Drug Content and Entrapment Efficiency

The Drug content and Entrapment Efficiency were calculated and displayed in the table 2.

\section{Standard Calibration Curve}

The standard calibration curve for copper nanoparticles (B) in phosphate buffer $\mathrm{pH} 7.4$ at $650 \mathrm{~nm}$ was shown in Fig. 8.
Antimicrobial activity by Resazurin microtitre assay

The synthesised $\mathrm{NS}_{4} \mathrm{Cu}_{\mathrm{B}}$ microsponge formulation was selected for the biomedical applications due to its least particle size and better entrapment efficiency. The antimicrobial activity was done by Resazurin Microtitre assay (Table 3). It shows good antibacterial activity towards E. coli and B. subtilis whose MIC values are $125 \mu \mathrm{g} / \mathrm{mL}$ and $31.2 \mu \mathrm{g} / \mathrm{mL}$ respectively. From the results, it shows more active towards $B$. subtilis. The MIC values of copper nanoparticles loaded microsponge $\mathrm{NS}_{4} \mathrm{Cu}_{\mathrm{B}}$ is almost equal to that of the value of $\mathrm{CuNps}(\mathrm{B})$. [9] Similarly, $\mathrm{NS}_{4} \mathrm{Cu}_{\mathrm{B}}$ shows an excellent antifungal activity towards $C$. albicans whose MIC value is $62.5 \mu \mathrm{g} / \mathrm{mL}$ whereas the MIC value of $\mathrm{CuNps}(\mathrm{B})$ was found to be $250 \mu \mathrm{g} / \mathrm{mL}$. ${ }^{[9]}$ Hence, it is proven that the antifungal activity nature of copper nanoparticles loaded microsponge is enhanced.

(Antibacterial activity - STD- Streptomycin)

(Antifungal activity-STD- Amphotericin B)

\section{Antioxidant activity by DPPH assay}

The copper nanoparticles loaded microsponge formulation $\mathrm{NS}_{4} \mathrm{Cu}_{3}$ has an antioxidant potential of $59.5 \%$ (Table 4 ). The percentage scavenging activity of copper nanoparticles loaded microsponge is slightly lower than the value of standard BHT (Fig. 10). The CuNps(B) showed $21.7 \%$ of scavenging activity. [9] From the results, it shows that the antioxidant activity increases in the copper nanoparticles loaded microsponge formulation $\left(\mathrm{NS}_{4} \mathrm{Cu}_{\mathrm{B}}\right)$. This indicates the successful encapsulation of drug (CuNPs) within the microsponge. Therefore, the copper nanoparticles loaded microsponge enhanced the activity of CuNps. It reveals the porous nature of the outer surface of the sponge offers control on the release of drug.

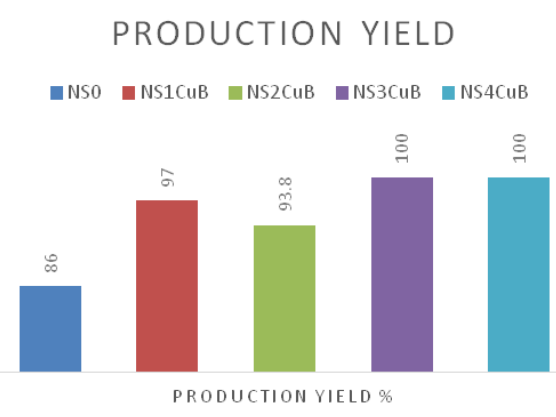

Fig. 7: Production yield of loaded and unloaded Microsponges Standard Calibration curve of $\operatorname{CuNps(B)}$

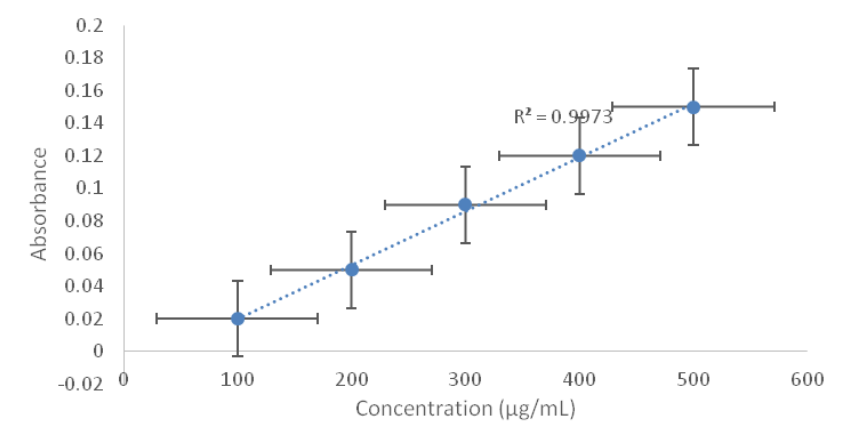

Fig. 8: Standard calibration curve of CuNps (B) 
Table 2: Drug Content and Entrapment Efficiency \% of Microsponge formulations

\begin{tabular}{cccccc}
\hline Sample Code & Absorbance & Concentration & Drug Content \% & Theoretical Drug Content \% in 10 mg & Entrapment Efficiency \% \\
\hline $\mathrm{NS}_{1} \mathrm{Cu}_{\mathrm{B}}$ & 0.121 & 403.33 & $4.0333 \pm 0.0183$ & 0.0497 & $81.07 \pm 0.3438$ \\
$\mathrm{NS}_{2} \mathrm{Cu}_{\mathrm{B}}$ & 0.113 & 376.67 & $3.7667 \pm 0.2269$ & 0.0332 & $113.37 \pm 6.8016$ \\
$\mathrm{NS}_{3} \mathrm{Cu}_{\mathrm{B}}$ & 0.149 & 496.67 & $4.9667 \pm 0.1836$ & 0.0497 & $99.83 \pm 3.6701$ \\
$\mathrm{NS}_{4} \mathrm{Cu}_{\mathrm{B}}$ & 0.135 & 450 & $4.50 \pm 0.0839$ & 0.0332 & $135.46 \pm 2.4837$ \\
\hline
\end{tabular}

Table 3: Antimicrobial activity of Copper nanoparticles(B) loaded Microsponge formulation $\mathrm{NS}_{4} \mathrm{Cu}_{\mathrm{B}}$

\begin{tabular}{ccccccccccccc}
\hline S. & Microorganisms/sample & \multicolumn{10}{c}{ Growth of inhibition $(\mu \mathrm{g} / \mathrm{mL})$} \\
\cline { 2 - 15 } & NS4Cu & $\mathbf{1 0 0 0}$ & $\mathbf{5 0 0}$ & $\mathbf{2 5 0}$ & $\mathbf{1 2 5}$ & $\mathbf{6 2 . 5}$ & $\mathbf{3 1 . 2}$ & $\mathbf{1 5 . 6}$ & $\mathbf{7 . 8}$ & STD 10 & Sterile water & Culture \\
\hline 1 & Escherichia coli & - & - & - & - & + & + & + & + & - & + \\
2 & Bacillus subtilis & - & - & - & - & - & - & + & + & - & + \\
3 & Candida albicans & - & - & - & - & - & + & + & + & - & + \\
\hline
\end{tabular}

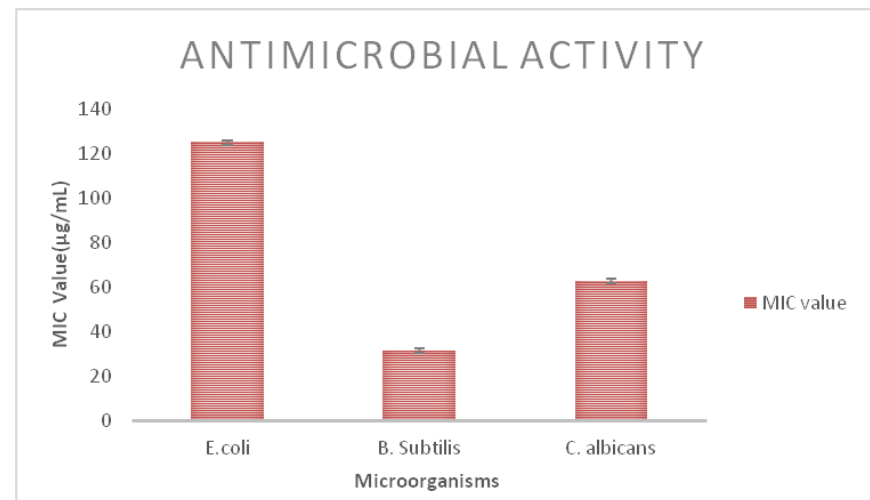

Fig. 9: Antimicrobial activity representing $\mathrm{MIC}$ value of $\mathrm{NS}_{4} \mathrm{Cu}_{\mathrm{B}}$

\section{ANTIOXIDANT ACTIVITY}

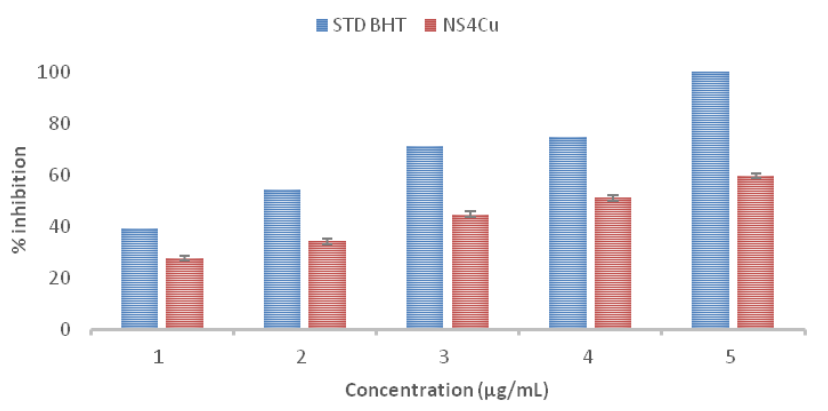

Fig .10. Antioxidant activity of NS4CuB by DPPH assay.

Table 4: Antioxidant activity of Copper nanoparticles(B) loaded Microsponge formulation $\mathrm{NS}_{4} \mathrm{Cu}_{\mathrm{B}}$

Standard -BHT (Butylated hydroxytoluene)

\begin{tabular}{ccccc}
\hline Concentration & \multicolumn{2}{c}{$\begin{array}{c}\text { Standard BHT } \\
\text { Blank - 0.59 }\end{array}$} & \multicolumn{2}{c}{$\begin{array}{c}\mathbf{N S}_{\mathbf{4}} \mathbf{C u}_{\mathrm{B}} \\
\text { Blank - 0.47 }\end{array}$} \\
\hline $\boldsymbol{\mu g} / \mathbf{m L}$ & O.D & \% inhibition & O.D & \% inhibition \\
\hline 100 & 0.36 & 38.9 & 0.34 & $27.6 \pm 0.15$ \\
200 & 0.27 & 54.2 & 0.31 & $34.0 \pm 0.5$ \\
300 & 0.17 & 71.1 & 0.26 & $44.6 \pm 0.5$ \\
400 & 0.15 & 74.5 & 0.23 & $51.0 \pm 0.5$ \\
500 & 0.11 & 99.8 & 0.19 & $59.5 \pm 0.7$ \\
\hline
\end{tabular}

Ethyl cellulose based microsponges loaded with copper nanoparticles green synthesised from the leaf extract of Hibiscus rosa-sinensis have been successfully prepared by Quasi-Emulsion solvent diffusion method. The formulated batches of microsponges were characterised by SEM and PSA. The SEM results showed smooth outer surface and porous spherical in nature. The least particle size of $65 \mu \mathrm{m}$ of $\mathrm{NS}_{4} \mathrm{Cu}_{\mathrm{B}}$ was selected for the biomedical applications.

The physicochemical parameters of the formulated microsponges including production yield, Drug content and entrapment efficiency were determined. The $\mathrm{NS}_{4} \mathrm{Cu}_{B}$ with least particle size showed better entrapment efficiency of $135 \%$. The antibacterial activity of copper nanoparticles loaded microsponge formulation $\mathrm{NS}_{4} \mathrm{Cu}_{\mathrm{B}}$ shows good activity on $B$. subtilis. The MIC values of CuNps loaded microsponge is equivalent to that of the drug (CuNps). Similarly, the antifungal activity of $\mathrm{NS}_{4} \mathrm{Cu}_{\mathrm{B}}$ towards $C$. albicans is increased when compared to that of CuNps. The antioxidant activity of $\mathrm{NS}_{4} \mathrm{Cu}_{\mathrm{B}}$ showed an enhanced activity of $59.5 \%$ to that of the CuNps (21.7\%).

In this work, we have made an attempt to incorporate copper nanoparticles in microsponge for the first time. We have succeeded in our venture by encapsulating CuNps in the microsponge formulation, thereby enhancing the activity of the copper nanoparticles. The smooth and porous nature of the formulation offers good control on release of the drug and hence it can be used in topical application in future.

\section{ACKNOWLEDGEMENT}

We profusely thank Dr. Sundar Mayavan, Scientist, CSIR-CECRI, Karaikudi for helping us in HRSEM of our work.

\section{REFERENCES}

1. Katkade M, Kalkotwar R, Jain N, Patil P, Gadhak R, Naikwade J. Ethylcellulose based microsponge Delivery system foe Anti-Fungal Vaginal Gels of Tioconazole. Journal of Drug Delivery \& Therapeutics. 2013; 3(6): 14-20.

2. Vyas LK, Tapar KK, Laddha BH, Lahoti AO, Nema RK. Formulation and development of anti-blemish preparation using microsponge technology. J. Chem. Pharm. Res. 2010; 2(5): 562-573.

3. Zhou Y, Kong Y, kundu S D, Cirillo J, Liang H. Antibacterial activities of gold and silver nanoparticles against Escherichia coli and bacillus Calmette-Guerin. J. Nanobiotech. 2012; 10(19): 1-9.

4. Travan A, Pelillio C, Donati I, Marsich E, Benincasa M, Scarpa T, Semeraro S, Turco G, Gennaro R, Paoletti S. Noncytotoxic silver nanoparticle polysaccharide nanocomposites with antimicrobial activity. Biomacromol. 2009; 10(6): 1429 1435.

5. Pinto RJ, Marques PA, Netro CP, Trindade T, Diana $S$, Sadocco P. Antibacterial activity of nanocomposites of silver and bacterial or vegetable cellulose fiber. Acta Biomater. 2009; 5(6): 2279-2289.

6. Syed Ahamed Hussain I, Jaisankar V. An eco-friendly synthesis, Characterisation and antibacterial applications of novel almond Gum- poly (Acrylamide) based hydrogel silver Nanocomposite. Polymer Testing. 2017; 62: 154-161. 
S. Kothai et al. / Formulation and Evaluation of Copper Nanoparticles Loaded............

7. Aloorkar NH, Kulkarni AS, Ingale DJ, Patil RA. Microsponges as Innovative Drug Delivery Systems. International Journal of Pharmaceutical Sciences and Nanotechnology. 2012; 5(1):1597-1606.

8. Resmi DS, Mathew P, Dev AP, Abraham E. Formulation and Evaluation of Topical Econazole Nitrate Microsponge Loaded Hydrogel. Ijppr. Human. 2018; 12(1): 27-64.
9. Kothai S, Umamaheswari R. Evaluation of antimicrobial and antioxidant activity of Green synthesized Copper nanoparticles from the leaf extract of Hibiscus rosa-sinensis. International Journal of Green and Herbal Chemistry. 2018; 7(4): 834-842.

HOW TO CITE THIS ARTICLE: Kothai S, Umamaheswari R. Formulation and Evaluation of Copper Nanoparticles Loaded Microsponges. Int. J. Pharm. Sci. Drug Res. 2019; 11(4): 141-146. DOI: 10.25004/IJPSDR.2019.110407 